\title{
Physicians' Knowledge and Attitudes Regarding Point-of-Care Pharmacogenetic Testing: A Hospital-Based Cross-Sectional Study
}

\author{
Suhaib Muflih (D) \\ Osama Y Alshogran (D) \\ Sayer Al-Azzam ' \\ Ghaith Al-Taani ${ }^{2}$ \\ Yousef S Khader (D) $^{3}$ \\ 'Department of Clinical Pharmacy, Jordan \\ University of Science and Technology, \\ Irbid, 22I I0, Jordan; ${ }^{2}$ Department of \\ Pharmacy Practice, Yarmouk University, \\ Irbid, Jordan; ${ }^{3}$ Department of Public \\ Health, Jordan University of Science and \\ Technology, Irbid, 22 I I0, Jordan
}

Correspondence: Suhaib Muflih

Faculty of Pharmacy, Jordan University of Science and Technology, Irbid, 22II0, Jordan

Tel +962-79-7868603

Email smmuflih@just.edu.jo
Introduction: Pharmacogenetic testing (PGx) is a diagnostic technique used by physicians to determine the possible reactions of patients to drug treatment on the basis of their genetic makeup. The aim of this study was to determine the impact of physicians' awareness, attitudes, and sociodemographics on the adoption of point-of-care (POC) PGx testing as a diagnostic method, as well as the impact of their knowledge, attitudes, and sociodemographics on its adoption.

Methods: A cross-sectional survey of 200 physicians and medical trainees working at the Clinics of King Abdullah University Hospital in Jordan was performed. Data on sociodemographics, knowledge and attitudes concerning PGx testing, genetic information sources, and barriers to POC-PGx testing adoption were gathered.

Results: Participants' perceived knowledge of the role of PGx testing in therapeutic decision-making was rated as "Excellent" (1.9\%), "Very Good" (19.4\%), "Good" (34.4\%), "Fair" (32.5\%), and "Poor" (11.9\%). Physicians' actual knowledge of PGx testing was adequate (mean=3.56 out of $7, \mathrm{SD}=1.2$ ), but their attitudes were generally favorable (mean=3.64 out of 5.00, $\mathrm{SD}=0.52$ ). According to Rogers' theory, many variables (eg, perceived need, relative advantage, compatibility) had a significant impact on physicians' willingness to endorse POC-PGx testing.

Discussion: The majority of physicians stated that they were unaware of PGx testing. Physicians' perceived knowledge of POC-PGx testing, however, was higher than those who participated in other studies. Participants were optimistic about the future benefits of PGx testing in prescribing effective medications and reducing potential side effects, which were consistent with previous studies. Physicians' willingness to accept and implement POCPGx testing was hampered by a lack of PGx expertise, as well as concerns about patient confidentiality, employability, and insurability. More training and genetic courses are needed, according to the majority of participants.

Keywords: pharmacogenetics, physicians, knowledge, attitudes, point-of-care, Rogers theory

\section{Introduction}

In the human genetic revolution, genome-wide association studies (GWAS) play a critical role to find common variables and new single nucleotide polymorphisms (SNPs) in an individual's entire genome. GWAS can be used to examine the possibility of genetic variants that may be linked to disease growth, interindividual variations in drug response and dosing, ${ }^{1}$ and adverse drug reactions (ADRs). ${ }^{2}$ While several environmental, clinical, and physiological factors influence 
individual drug response, predisposing genetic factors account for up to $40 \%$ of the observed interindividual variations in drug effects. ${ }^{3,4}$ Individual variability in genetically determined pharmacokinetics and pharmacodynamics has been recognized as a key component of drug response, and pharmacogenetic tests (PGx) have been suggested as a way toward improving personalized medicine. ${ }^{5}$ ADRs can have a significant impact on patient's health outcomes, particularly in the elderly and those with multiple comorbidities, ${ }^{6}$ as well as the healthcare system's financial burdens. Reports showed that $5-10 \%$ and $2.3 \%$ of all hospital admissions and immediate deaths were due to ADRs. ${ }^{7,8}$

Despite the fact that some research revealed a positive attitude among psychiatrists toward implementing genetically guided treatment decisions, ${ }^{9,10}$ several studies revealed a lack of familiarity with the nature and potential benefits of PGx testing, ambiguity about evidence relevant to PGx testing's clinical utility, and uncertainty about the cost-effectiveness of such testing. ${ }^{1-13}$ Other studies also suggested that the lack of PGx-related educational and training programs may have an effect on the acceptance of these tests. ${ }^{14,15}$ During a 3-month follow-up observational study, Ielmini et al published contradictory findings. ${ }^{16}$ They wanted to see whether PGx testing could help psychiatrists reach a more successful and tolerated treatment currently available for bipolar disorder in routine practice. The authors confirmed that clinicians preferred to keep the same treatment even though the PGx recommended an alternative therapy mainly due to ADRs rather than a lack of effectiveness, implying a lack of confidence in these genetic tests' indications. ${ }^{16}$ In a separate preliminary report, Ielmini et al supported the value of PGx research in assisting physicians in the pursuit of personalized medicine. ${ }^{17}$ Roberts et al performed a prospective randomized study on 187 patients with the aim of evaluating a PGx approach to antiplatelet therapy following percutaneous coronary intervention (PCI). ${ }^{18}$ Point-of-care (POC)-PGx testing was used to classify carriers of the CYP2C19*2 allele, which may reduce clopidogrel's therapeutic benefit. POC, according to the authors, enabled healthcare providers with no prior training in genetic laboratory techniques to effectively genotype CYP2C19*2 carriers at the bedside and reducing major adverse cardiovascular events compared with those given standard treatment. ${ }^{18}$

Near-patient monitoring, also known as POC testing, provides physicians with patient findings at the time of care, allowing them to make timely treatment decisions that could enhance the patients' health outcomes. ${ }^{19}$ POCPGx research allows for the analysis of one or two genes linked to a particular drug ${ }^{2}$ and can be used in a number of settings. ${ }^{20}$ POC-PGx testing is also useful for improving dosing for inpatients and outpatients who benefit from office-based testing, it offers rapid testing platforms and reduces the potential for care delays caused by long test processing times. ${ }^{18,21,22}$ Studies showed that POC-PGx screening for genes involved in the therapeutic outcomes of warfarin ${ }^{23,24}$ and clopidogrel ${ }^{18}$ has been demonstrated to be feasible and effective in a variety of medical specialties (eg, internal and family medicine) in both inpatient and outpatient settings. Many health institutions in Jordan depend on external laboratory centers to provide clinical genotyping services. Clopidogrel and warfarin are individualized and appropriate for point-of-care in many Jordanian institutions, including KAUH, due to this rapid advancement of sequence technology and low cost. ${ }^{25}$ Nearly 300 drug-package inserts have been approved by the FDA that provide information on PGx biomarkers, such as germline and somatic gene variants (eg, mutations) as well as functional defects that can be evaluated and regarded by both physicians and pharmacists. ${ }^{26}$ However, POC-PGx testing has only been used in clinical practice on a few occasions, and the clinical utility of PGx is yet to be determined for medications with FDA-approved PGx labeling. The majority of participating physicians had never requested a PGx test due to, in part, a lack of information on which tests to order (70\%), and the lack of insurance coverage for such tests (53\%). ${ }^{14,27}$ In Jordan, there is limited information on healthcare providers' awareness and adoption of POC-PGx. ${ }^{25}$ The current study focused on the first three stages of Rogers' Diffusion of Innovation (DOI) theory, which involves the knowledge and attitude stages, both of which are essential in the innovation acceptance process. ${ }^{28,29}$

The aims of this study were to (1) assess physicians' perceived knowledge, actual knowledge, and attitudes toward POC-PGx testing, (2) determine if their knowledge or attitude changed as a result of sociodemographic factors as well as Rogers' theory-based variables of interest, (3) identify the barriers to implementing POC-PGx testing, and (4) investigate the predictive function of knowledge and attitudes on physicians' acceptance of POC-PGx testing.

\section{Method}

\section{Study Design and Setting}

This was a cross-sectional descriptive study carried out between July 1st and October 18th, 2019. A 
self-administered questionnaire was used to collect participant data and included information on sociodemographic characteristics (eg, age, gender, medical specialty, duration of practice, current practice setting), previous experience with PGx testing, perceived need for such testing, factors that may influence the attitude of a person towards PGx research, such as compatibility, relative benefit, sophistication, genetic knowledge sources, trialability, and inhibitors of PGx adoption. The research was performed at the University of King Abdullah Hospital (KAUH). The hospital, located in Irbid, Jordan, has a bed capacity of 683 .

\section{The Study Population}

The population included full-time and part-time physicians and medical trainees (ie, residents, fellows, and specialists) practicing at KAUH's Clinics. The potential participants were invited on-site to participate in this study $(\mathrm{n}=450)$. Participants who were currently practicing medicine, showed interest to participate, and were willing to sign a consent form (see Appendix A), were included in the study to fill the paper-based questionnaire.

\section{Development of the Survey Instrument}

The researcher developed this questionnaire based on the available research literature on PGx testing and Rogers' Diffusion of Innovation (DOI) theory, which used validated surveys, methods, and concepts to serve similar objectives. ${ }^{15,30-34}$ Further, a group of five faculty members assisted in generating preliminary qualitative work to create items for the attitude scale and the overall questionnaire content. Before distribution, the faculty members evaluated the reliability as well as the face and content validity of the developed tool to verify that readability, order and clarity of the questions meet the required standards. A pilot test was conducted with a group of 15 physicians to determine the clarity of the POC concept and to ensure the questionnaire components' suitability, readability, comprehension. Following pilot testing, repeated statements were omitted, double-barreled questions were rephrased, and possible language mistakes that could jeopardize the instrument's validity were corrected. Furthermore, POC-PGx was explicitly stated in the survey and invitation letter. The final questionnaire was condensed to 35 items (see Appendix B). An average completion time was reported as ten minutes.

The prescribers' questionnaire consisted of 35 questions. Seven items were used to assess prescribers' knowledge of
POC-PGx testing. Six-item and five-item scales were used to measure their attitudes toward the clinical utility of POCPGx testing and its innovative characteristics, respectively. A single item was used to assess prescribers' willingness to accept POC-PGx testing. Cronbach's alpha was calculated to establish the internal consistency of the knowledge, attitude and characteristic of innovation items, showing scores of $0.70,0.78$, and 0.81 , respectively. The 5-point Likert scale was used to assess the levels of agreement of physicians with the attitude and characteristics of innovation statements, giving a point value (Strongly Disagree $=1$, Disagree $=2$, Neutral $=3$, Agree $=4$, and Strongly Agree $=5$ ) to each response in order to evaluate and rank the results as follows:

- (1.00-2.33) Low score (Low Rank).

- (2.34-3.67) Medium score (Medium Rank).

- (3.68-5) High score (High Rank).

This study's primary outcome was 'respondents' adequate knowledge and optimistic attitude toward PGx testing." A respondent's adequate knowledge of PGx testing was described as "yes" if they correctly answered $>50 \%$ of questions (4 questions out of 7); correct answers were coded as "1." Incorrect or not sure responses were marked with a "0." The respondent's attitude toward PGx research was assessed using six statements. If the respondent answered $>50 \%$ of the questions with agree or strongly agree, the overall respondents' attitude toward PGx testing was described as "positive attitude." Secondary outcomes included the relationships between participants' sociodemographic characteristics and their knowledge of and attitudes toward PGx testing. Based on Rogers' theory, several factors influence the stages of knowledge and attitudes such as sociodemographic variables, the perceived need, prior experience, innovativeness, compatibility, complexity, relative advantage, trialability, and observability. ${ }^{28}$ Together, knowledge and attitudes play a key role in the acceptance process of innovation. ${ }^{29}$ The total composite scores for the PGx testing knowledge and attitudes were calculated for each participant. Further, a composite score of Rogers' theorybased characteristics of innovation comprising of relative advantage, compatibility, trialability, complexity, and observability, was also calculated.

\section{Data Collection and Statistical Analysis}

The collected data was transferred to IBM ${ }^{\circledR}$ SPSS version 24.0. The key investigator reconciled the data to ensure accuracy and to resolve any errors in data entry. In order 
to describe and summarize nominal and continuous data, univariate analysis was performed. For continuous variables, the measurements of central tendency have been determined. For categorical variables, counts and percentages were utilized. After checking the fulfillment of the theoretical assumptions, statistical packages IBM $^{\circledR}$ SPSS version 24.0 was utilized to perform the $t$-test, one-way analysis of variance (ANOVA), chi-square, and the linear and logistic regression models as appropriate. To investigate variations between multiple groups means, posthoc Tukey's tests were also used. P-values less than 0.05 were considered significant in all tests. Multiple comparisons were adjusted using the Bonferroni correction, which is one of the most commonly used techniques for multiple comparisons. Raosoft ${ }^{\circledR}$ was utilized to estimate the appropriate sample size using a significance level of 0.05 and a $5 \%$ error margin with a statistical power of 0.08 , which was determined to consist of 200 observations. $^{35}$

\section{Ethical Considerations}

Prior to the commencement of this research, the study protocol, anonymous survey, and consent form were submitted and approved by the Institutional Review Board (IRB, approval ID: 30/120/2019) at the Jordan University of Science and Technology's (JUST). Under the Health Insurance Portability and Accountability Act (HIPAA), the study also enforced data privacy requirements.

\section{Results}

\section{Study Sample Characteristics}

The Jordan Medical Association (JMA) has enrolled approximately 28,000 physicians $(60 \%$ male and $40 \%$ female) since its inception in 1954, with $22.9 \%$ working in the public sector and $17.9 \%$ in the private sector. ${ }^{36}$ The paper-based survey was completed by 200 physicians, with a response rate of $44.44 \%$. The majority of the participants were female (median age, 38 years) and more likely to practice internal and family medicine. In general, participants practiced medicine for a medium period of 1-10 years, mostly in urban settings (see Table 1).

\section{Sources of Genetic Information}

Physicians who participated in this study were asked to state their main source of genetic information. Only $11.3 \%$ of participants reported not having received education in genetics. The findings showed that almost $45.6 \%$ of
Table I Percentage Distribution of Selected Demographic Variables of Prescribers in the Sample $(N=200)$

\begin{tabular}{|l|c|}
\hline Variables & Frequency (\%) \\
\hline Gender & - \\
Male & $85(42.5)$ \\
Female & $115(57.5)$ \\
\hline Medical specialty & - \\
Internal Medicine & $95(47.5)$ \\
Family Medicine & $54(27.0)$ \\
General Surgery & $20(10.0)$ \\
Pediatrics & $15(7.5)$ \\
Others & $16(8.0)$ \\
\hline Duration of practice (years) & - \\
I-5 & $85(42.5)$ \\
6-10 & $55(27.5)$ \\
II-15 & $22(11.0)$ \\
More than I6 & $38(19.0)$ \\
\hline The setting of physicians' primary practice & - \\
Urban & $170(85.0)$ \\
Suburban & $30(15)$ \\
\hline
\end{tabular}

respondents had received genetic information through genetics training in medical school followed by $21.9 \%$ from undergraduate genetic courses and 15\% from genetics-related seminars or workshops. Genetics training in residency $(3.8 \%)$ and continuing medical education $\mathrm{CME}$ $(6.3 \%)$ sources were the least commonly stated sources of genetics' information. Other sources, such as the Internet and scientific websites, were also reported.

\section{Perceived Level of Knowledge of POC-PGx Testing Among Physicians}

When participants were asked about their current understanding of the pharmacogenetics role in therapeutic decision-making, they rated their perceived knowledge as "Excellent" (1.9\%), "Very Good" (19.4\%), "Good" (34.4\%), "Fair" (32.5\%) and "Poor" (11.9\%). This study found a significant relationship between physicians' perceived knowledge, and the availability of PGx testing at their place of employment $(\mathrm{r}(159)=0.250, p<0.05)$, participation in the implementation of PGx testing, either in ordering testing or translating results $(\mathrm{r}(159)=0.488, p<$ $0.05)$, previous communication with patients about the role of PGx testing in personalized medicine $(\mathrm{r}(159)=0.443, p<$ $0.05)$, and physicians' attitudes towards the clinical utility of POC-PGx testing $(\mathrm{r}(159)=0.175, \mathrm{p}<0.05)$. 


\section{Prescribers' Actual Knowledge of POC- PGx Testing}

The mean actual knowledge score was 3.56 out of 7.00 , with a standard deviation of 1.2. The majority of physicians knew about the genetic-based variability of an individual's response to medications and the potential side effects (see Table 2). To determine the relationship between physicians' knowledge of POC-PGx testing and sociodemographic characteristics, the $t$-test and one-way ANOVA were performed. The empirical evidence here exhibited that duration of practice $(F(3196)=4.98, p<$ $0.05)$, prior experience $(t(198)=5.11, p<0.05)$, willingness of accepting PGx testing $(t(198)=2.46, p<$ $0.05)$, medical specialty $(F(3195)=3.58, p<0.05)$, and number of information sources $(F(2197)=6.42, p<0.05)$ had significantly demonstrated variations in scores of knowledge on POC-PGx testing (see Table 3). The significant predictors found in the t-tests and one-way ANOVA tests were applied to generate a linear regression model, with $p<0.05$ indicating statistical significance. A significant regression equation was found $(F(7192)$

Table 2 Prescribers' Actual Knowledge of Pharmacogenetic Testing

\begin{tabular}{|c|l|c|}
\hline \multicolumn{2}{|l|}{} & $\begin{array}{c}\text { Correctly } \\
\text { Answered (\%) }\end{array}$ \\
\hline I & $\begin{array}{l}\text { A patient's genetic make-up influencing drug } \\
\text { response can change over a person's lifetime }\end{array}$ & $12(6)$ \\
\hline 2 & $\begin{array}{l}\text { Genetic variations can account for as much } \\
\text { as 95\% of the variability of an individual's } \\
\text { response to a medication }\end{array}$ & $84(42)$ \\
\hline 3 & $\begin{array}{l}\text { People with genetic differences can respond } \\
\text { differently to the same medication }\end{array}$ & $139(69.5)$ \\
\hline 4 & $\begin{array}{l}\text { Pharmacogenetic testing is currently } \\
\text { available for all medications }\end{array}$ & $62(31)$ \\
\hline 5 & $\begin{array}{l}\text { The Food and Drug Administration (FDA) } \\
\text { has revised drug labels of warfarin to include } \\
\text { information about pharmacogenetics }\end{array}$ & $70(35)$ \\
\hline 6 & $\begin{array}{l}\text { FDA has revised drug labels of clopidogrel } \\
\text { (Plavix) to include information about } \\
\text { pharmacogenetics }\end{array}$ & $65(32.5)$ \\
\hline 7 & $\begin{array}{l}\text { The intensity of adverse events of some } \\
\text { medications may depend on a person's } \\
\text { genetic make-up }\end{array}$ & $147(73.5)$ \\
\hline
\end{tabular}

Notes: The correct answer for questions I and 4 is "No" the correct answers for questions 2, 3, 5, 6, 7 is "Yes".
Table 3 Relationships Between Knowledge and Attitudes Towards PGx Testing and Variables of Interest ( $t$-Test and ANOVA)

\begin{tabular}{|c|c|c|c|c|}
\hline \multirow[t]{2}{*}{ Variable } & \multicolumn{2}{|c|}{ Knowledge } & \multicolumn{2}{|c|}{ Attitude } \\
\hline & Mean & SD & Mean & SD \\
\hline \multicolumn{5}{|l|}{ Gender } \\
\hline Male & 3.53 & 1.57 & 3.79 & 0.46 \\
\hline Female & 3.58 & 1.48 & 3.60 & 0.56 \\
\hline$P$ value & \multicolumn{2}{|l|}{0.820} & \multicolumn{2}{|l|}{0.011} \\
\hline \multicolumn{5}{|l|}{ Duration of Practice } \\
\hline $1-5$ & 3.31 & 1.25 & 3.54 & 0.51 \\
\hline $6-10$ & 3.26 & 1.32 & 3.58 & 0.44 \\
\hline $11-15$ & 3.42 & $|.5|$ & 3.88 & 0.60 \\
\hline More than 16 & 5.24 & 1.24 & 4.02 & 0.48 \\
\hline$P$ value & \multicolumn{2}{|l|}{0.000} & \multicolumn{2}{|l|}{0.000} \\
\hline \multicolumn{5}{|l|}{ Medical Specialty } \\
\hline Internal Medicine & 3.39 & 1.35 & 3.70 & 0.54 \\
\hline Family Medicine & 4.03 & 1.53 & 3.69 & 0.57 \\
\hline General Surgery & 3.56 & 1.60 & 3.70 & 0.49 \\
\hline \multirow[t]{2}{*}{ Pediatrics and other } & 2.96 & 1.40 & 3.48 & 0.43 \\
\hline & \multicolumn{2}{|l|}{0.009} & \multicolumn{2}{|l|}{0.276} \\
\hline \multicolumn{5}{|l|}{$\begin{array}{l}\text { The setting of physicians' } \\
\text { primary practice }\end{array}$} \\
\hline Urban & 3.58 & 1.47 & 3.70 & 0.51 \\
\hline \multirow[t]{2}{*}{ Suburban } & 3.47 & 1.58 & 3.53 & 0.59 \\
\hline & \multicolumn{2}{|l|}{0.690} & \multicolumn{2}{|l|}{0.110} \\
\hline \multicolumn{5}{|l|}{$\begin{array}{l}\text { Number of Sources of } \\
\text { information used }\end{array}$} \\
\hline I-2 sources & 3.26 & 1.26 & 3.56 & 0.59 \\
\hline $3-4$ sources & 3.38 & 1.47 & 3.70 & 0.54 \\
\hline \multirow[t]{2}{*}{ More than 4 sources } & 4.11 & 1.52 & 3.66 & 0.47 \\
\hline & \multicolumn{2}{|l|}{0.006} & \multicolumn{2}{|l|}{0.471} \\
\hline \multicolumn{5}{|l|}{$\begin{array}{l}\text { Prior Experience with POC- } \\
\text { PGx testing }\end{array}$} \\
\hline Yes $(n=4 I)$ & 4.49 & 1.47 & 3.81 & 0.58 \\
\hline \multirow[t]{2}{*}{ No $(n=159)$} & 3.33 & 1.41 & 3.63 & 0.51 \\
\hline & \multicolumn{2}{|l|}{0.000} & \multicolumn{2}{|l|}{0.059} \\
\hline \multicolumn{5}{|l|}{$\begin{array}{l}\text { Willingness to accept PGx } \\
\text { testing }\end{array}$} \\
\hline Yes & 3.80 & 1.50 & 3.78 & 0.49 \\
\hline No & 3.02 & 1.33 & 3.42 & 0.54 \\
\hline$P$ value & \multicolumn{2}{|l|}{0.001} & \multicolumn{2}{|l|}{0.000} \\
\hline
\end{tabular}

Notes: T-tests or ANOVA were used to analyze the data as appropriate, with $p<0.05$ indicating statistical significance.

$=8.8, p<0.05$ ) with an $\mathrm{R}^{2}$ of 0.265 . The regression model revealed that prior experience, duration of 
Table 4 Mean, Standard Deviations, and Ranks of Characteristics of PGx Innovation, Rogers' Theory-Based Questions

\begin{tabular}{|c|c|c|c|c|c|c|c|c|}
\hline \multirow[t]{2}{*}{ Item } & \multicolumn{5}{|c|}{ Frequency (\%) } & \multirow[t]{2}{*}{$\mathbf{M}$} & \multirow[t]{2}{*}{ SD } & \multirow[t]{2}{*}{ Rank } \\
\hline & SD & D & $\mathbf{N}$ & $\mathbf{A}$ & SA & & & \\
\hline $\begin{array}{l}\text { Perceived need } \\
\text { POC-PGx testing is crucial in cases with non- } \\
\text { response or potential life-threatening drug } \\
\text { reactions }\end{array}$ & $4(2)$ & $4(2)$ & $\mathrm{II}(5.5)$ & $94(47)$ & $87(43.5)$ & 4.28 & 0.8 & I \\
\hline $\begin{array}{l}\text { Relative advantage } \\
\text { I believe that POC-PGx testing will help to } \\
\text { decrease the number of adverse drug events }\end{array}$ & $2(1)$ & $9(4.5)$ & $14(7)$ & $94(47)$ & $81(40.5)$ & 4.22 & 0.84 & 2 \\
\hline $\begin{array}{l}\text { Compatibility } \\
\text { POC-PGx testing is compatible with the current } \\
\text { practice of prescribing and mentoring } \\
\text { medications }\end{array}$ & $8(4)$ & $22(I I)$ & $60(30)$ & $47(23.5)$ & $63(31.5)$ & 3.68 & I.I & 3 \\
\hline $\begin{array}{l}\text { Complexity } \\
\text { POC-PGx testing is difficult to deal with in the } \\
\text { current clinical practice compared to other } \\
\text { routine lab tests }\end{array}$ & $8(4)$ & II (5.5) & $61(30.5)$ & $86(43)$ & $34(17)$ & 3.64 & 0.9 & 4 \\
\hline $\begin{array}{l}\text { Trialability } \\
\text { I would like to try POC-PGx testing if offered as } \\
\text { free samples }\end{array}$ & $8(4)$ & $13(6.5)$ & $58(29)$ & $87(43.5)$ & $34(17)$ & 3.63 & 0.9 & 5 \\
\hline $\begin{array}{l}\text { Innovativeness } \\
\text { I would like to adopt POC-PGx testing as soon } \\
\text { as it becomes available }\end{array}$ & $5(2.5)$ & $12(6)$ & $77(38.5)$ & $7 I(35.5)$ & $35(17.5)$ & 3.60 & 0.93 & 6 \\
\hline $\begin{array}{l}\text { Observability } \\
\text { The clinical outcomes of using POC-PGx testing } \\
\text { are visible at my workplace }\end{array}$ & $4 I(20.5)$ & $74(37)$ & $26(13)$ & $48(24)$ & $\mathrm{II}(5.5)$ & 2.57 & 1.2 & 7 \\
\hline
\end{tabular}

Abbreviations: SD, strongly disagree; D, disagree; N, neutral; A, agree; SA, strongly agree; $M$, mean; SD, standard deviation.

practice, willingness to accept PGx testing and number of information sources were significant predictors of actual knowledge.

\section{Rogers' Diffusion of Innovation Framework}

When participants were asked about the characteristics of PGx testing that might influence their perceptions and opinions, the majority had high attitudes toward the need and the relative advantage of POC-PGx testing. Most of the respondents agreed to the compatibility of POC-PGx testing with their current practice of medicine. However, the complexity of dealing with POC-PGx testing in the current clinical practice was also reported. The trialability of PGx testing led to a higher perception of its clinical utility. Participants ranked observability as the least satisfactory item (see Table 4).

\section{Prescribers' Attitudes Toward POC-PGx}

\section{Testing}

The mean attitude score was 3.64 out of 5.00, with a standard deviation of 0.52 . The majority of physicians agreed or strongly agreed about the role of POC-PGx testing in optimizing patients' safety, medications' efficacy, and prescribing the correct medication. Inability to control access to genetic data raised issues of confidentiality among participants (see Table 5). T-test and one-way ANOVA were conducted to assess the association between physicians' attitudes toward POC-PGx testing and sociodemographic characteristics. Analysis revealed significant effects of gender $(F(198)=4.48, p<0.05)$, duration of practice $(F(3196)=4.98, p<0.05)$ and willingness of accepting PGx testing $(F(198)=2.18, p<0.01)$ on the total score of attitude. Male physicians, those who had a longer duration of medical practice, and those who 
Table 5 Mean and Standard Deviations, and Ranks of Physicians' Attitudes Towards the Use of PGx Testing

\begin{tabular}{|c|c|c|c|c|c|c|c|c|}
\hline \multirow[t]{2}{*}{ Item } & \multicolumn{5}{|c|}{ Frequency (\%) } & \multirow[t]{2}{*}{$M$} & \multirow[t]{2}{*}{ SD } & \multirow[t]{2}{*}{ Rank } \\
\hline & SD & D & $\mathbf{N}$ & A & SA & & & \\
\hline $\begin{array}{l}\text { Pharmacogenetic testing can potentially optimize } \\
\text { the safety and efficacy of medication better than } \\
\text { the current traditional way of prescribing drugs. }\end{array}$ & $5(2.5)$ & II(5.5) & $38(19)$ & $89(44.5)$ & $57(28.5)$ & 3.91 & 0.96 & I \\
\hline $\begin{array}{l}\text { I think that pharmacogenetic testing may prevent } \\
\text { prescribing a wrong medicine }\end{array}$ & $\mathrm{I}(0.5)$ & $12(6.0)$ & $45(22.5)$ & $86(43)$ & $56(28)$ & 3.89 & 0.89 & 2 \\
\hline $\begin{array}{l}\text { I am concerned about the effect of the test } \\
\text { results on my patients' employment } \\
\text { opportunities }\end{array}$ & $29(14.5)$ & 66(33) & $82(4 I)$ & $18(9)$ & $5(2.5)$ & 2.52 & 0.93 & 3 \\
\hline $\begin{array}{l}\text { Pharmacogenetic testing will help in reducing the } \\
\text { cost of developing new drugs }\end{array}$ & $5(2.5)$ & $21(10.5)$ & $72(36)$ & $77(38.5)$ & $25(\mid 2.5)$ & 3.48 & 0.93 & 4 \\
\hline $\begin{array}{l}\text { I am concerned that unauthorized personnel may } \\
\text { gain access to the results of that test }\end{array}$ & $26(13)$ & $90(45)$ & $62(31)$ & $20(10)$ & $2(1)$ & 2.41 & 0.88 & 5 \\
\hline $\begin{array}{l}\text { I am concerned about the effect of the test } \\
\text { results on my patients' eligibility for private } \\
\text { health insurance }\end{array}$ & $29(14.5)$ & $94(47)$ & $58(29)$ & $14(7)$ & $5(2.5)$ & 2.36 & 0.90 & 6 \\
\hline
\end{tabular}

Abbreviations: SD, strongly disagree; D, disagree; N, neutral; A, agree; SA, strongly agree; $M$, mean; SD, standard deviation.

were willing to accept PGx testing had a higher overall attitude towards the clinical utility of POC-PGx testing than their counterparts. (See Table 3) The significant predictors found in the t-tests and one-way ANOVA were applied to generate a linear regression model. The regression equation was significant $(F(8191)=2.6, p<0.05)$ with an $\mathrm{R}^{2}$ of 0.382 , and the findings showed that duration of practice, relative $\mathrm{ARD}$, compatibility, complexity, and observability were significant predictors of attitudes towards POC-PGx testing.

\section{Barriers to POC-PGx Testing Implementation}

The findings of this study identified the perceived barriers to the implementation of POC-PGx testing. Factors such as lack of time (42.5\%) and technological gaps on gene sequencing $(38.5 \%)$ such as accuracy and cost were the most frequently reported barriers, followed by additional work needed for genetic interpretation (34\%), lack of compensation (19.5\%), uncertainty of genotyping prediction $(16.5 \%)$, and the potential harms of false-positive results to patients and their families (14.5\%). The findings revealed that physicians with a longer duration of medical practice and those who had prior experience with POC-
PGx testing reported fewer barriers to the adoption of POC-PGx testing.

\section{Acceptance of POC-PGx Testing}

Logistic regression was used to model the acceptance or rejection of POC-PGX testing. The results revealed that actual knowledge and the probability of accepting POCPGx testing had a positive predictor relationship. Acceptance of POC-PGx testing increases by a factor of 1.332 for every one unit increase in knowledge. Similarly, there was a positive predictor association between overall attitudes toward POC-PGx testing and the probability of accepting POC-PGx testing $(\mathrm{OR}=2.525, \quad \mathrm{P}=0.017)$. Interestingly, the relationship between the characteristics of innovation and the likelihood of accepting POC-PGx testing was at the borderline of significance (see Table 6).

\section{Discussion}

\section{Physicians' Perceived Knowledge of POC- PGx Testing}

Most physicians indicated that they were not aware of POC-PGx testing. However, physicians' perceived knowledge of POC-PGx testing was higher compared to those who participated in other studies..$^{14,15,30,37,38}$ Since the 
Table 6 Logistic Regression to Predict the Acceptance of POCPGx Testing

\begin{tabular}{|l|c|c|c|c|}
\hline Variables & B & S.E. & Sig. & OR \\
\hline Perceived Knowledge & -0.226 & 0.186 & 0.225 & 0.798 \\
\hline Actual Knowledge & 0.287 & 0.122 & 0.019 & 1.332 \\
\hline Overall Attitude & 0.926 & 0.386 & 0.017 & 2.525 \\
\hline Perceived Need & 0.283 & 0.404 & 0.483 & 1.328 \\
\hline Characteristics of Innovation & 0.743 & 0.385 & 0.054 & 2.102 \\
\hline Constant & -5.913 & 1.633 & 0.000 & 0.003 \\
\hline
\end{tabular}

Notes: A p-value less than 0.05 is statistically significant.

Abbreviations: B, regression coefficient; S.E., standard error; OR, odd ratio.

results of recent clinical trials become available, the findings here may reflect that physicians are becoming more receptive to POC-PGx testing and its clinical utility. The percentage of respondents who reported receiving a formal genetic education was higher than that reported in previous studies, ${ }^{14,27,39,40}$ which might correlate with the availability of additional teaching and training resources. Notably, there was a significant association between the number of sources of genetic information and the level of perceived POC-PGx knowledge, which was consistent with other studies. ${ }^{14,27,30,37,39}$ Participants who had practiced medicine for a longer period of time had lower perceived knowledge but higher actual knowledge. This misalignment between perceived and actual knowledge suggests that physicians, despite their years of clinical practice, may have a low comfort level with DNA-based technology and its complexity. In addition, only a few physicians had at least one PGx order for a chronic illness.

\section{Prescribers' Actual Knowledge of POC- PGx Testing}

According to the findings of this study, few physicians believed that genetic variability had an effect on drug responses. Furthermore, many participants were unaware that Plavix ${ }^{\circledR}$ (clopidogrel) PGx testing was available. A survey of healthcare workers in the Emirate found that their knowledge of PGx is fair, ${ }^{41}$ which is similar to the findings of this study.

In this study, family physicians outperformed internists on the PGx knowledge scale, suggesting that PGx research is especially useful to family physicians in terms of supporting safe and cost-effective therapies. Similar to previous research, this research found a connection between a lack of knowledge and a lack of experience with POCPGx testing, ${ }^{14,27,37}$ suggesting that prior experience is an essential aspect of learning about these novel tests and their applications. Furthermore, physicians with higher overall PGx testing knowledge perceived the need for POC-PGx testing in reducing ADRs and preventing unsuccessful therapies, which was consistent with the results published by Haga et al, Stanek et al.

In the current study, there was no significant gap in actual knowledge of POC-PGx research between men and women. Similar findings were reported by Albassam et al. ${ }^{42}$ Female practitioners in urban areas, however, were more likely to develop expertise than female practitioners in remote areas, possibly due to post-graduate training and seeing more patients on a daily basis. More research is needed to explore physicians' knowledge of PGx testing when practicing in urban or rural settings.

\section{Prescribers' Attitudes Toward POC-PGx Testing}

According to the results of this study, physicians have a favorable attitude toward POC-PGx testing and its clinical usefulness, which is consistent with the findings of other authors. ${ }^{14,39,40,43,44}$ This may be due to the pressing need to increase drug effectiveness and safety. In comparison to a previous survey, physicians in this study expressed fewer reservations about POC-PGx testing. ${ }^{15}$ There was no evidence that prior experience had an effect on physicians' attitudes in this study. This may be due to the use of a substandard attitude assessment instrument or a general lack of enthusiasm for POC-PGx. As a result, physicians can benefit from additional educational services, such as genomics continuing medical education. Similar attitudes toward POC-PGx testing have been reported across various medical specialties, indicating that they all agree on its perceived benefits. Male physicians in this sample had more favorable attitudes toward POC-PGx testing than female physicians, which is consistent with other studies. ${ }^{43,45}$ This may be because they were unconcerned about the potential consequences of POCPGx testing, such as stigma and discrimination. The more optimistic attitude associated with more practice time may represent physicians' views on the need for precision medicine. Haga et al also noted the effect of PGx testing's relative benefit on physicians' attitudes. Furthermore, using PGx testing resulted in substantial cost savings in terms of hospitalization number and days, 
as well as emergency care access, according to Callegari et al. ${ }^{46}$ Moreover, neither the trialability nor the observability variables were found to be related to POC-PGx testing attitudes. This may be attributed to physicians' unfamiliarity with PGx studies, as well as time constraints and the additional work needed for the interpretation of genetic results.

\section{Adoption (Acceptance) of POC-PGx Testing Among Physicians}

Participants' actual knowledge and overall attitudes toward POC-PGx testing were significant predictors of the intention to adopt POC-PGx testing, according to the current study's findings. Nearly half of the participants said they would consider POC-PGx testing in their clinics, implying that physicians are more confident in understanding and interpreting the results of PCO-PGx testing and believe it has a positive impact on patients' wellbeing. Physicians with insufficient knowledge and attitudes toward POC-PGx testing were less likely to order PGx testing, this lends support to previous findings. ${ }^{14,27,30,39}$ Thus, improving the perceived characteristics of POCPGx testing (eg, observability, relative advantage) will likely increase the perceived utility of these genetic tests. Finally, a greater proportion of physicians who reported a lack of time in their practice were able to accept POCPGx testing, which may indicate that they are more aware of the benefits of POC-PGx testing than those who reported having sufficient time.

\section{Limitations}

Attention should be called to the fact that some limitations may have influenced the obtained results. For example, a lack of generalizability, which was probably a result of the small sample size since there was a restricted ability to include a larger random representative sample. Therefore, future investigations among other healthcare workers such as pharmacists and nurses may be necessary. Moreover, the survey consisted of close-ended questions which may have resulted in lower validity. The honesty and transparency of the answers given cannot be confirmed, as respondents may not feel empowered to provide correct and truthful answers.

\section{Conclusion}

Despite the fact that prescribers' overall perceived knowledge of POC-PGx was fair to good and their actual knowledge was adequate, their attitudes were overly optimistic. POC-PGx testing was viewed more favorably by participants who had recently used it than those who had never used it. In a number of clinical settings, POC-PGx testing allows genotypedirected treatment to be tailored for each patient. It's more likely to uncover individual differences in drug response and increase the effectiveness and safety of long-term medications. This study emphasized the importance of expanding educational and training programs, as well as updating the medical curriculum to include more PGx courses so that physicians become more confident about discussing and communicating PGx testing results to their patients. More qualitative research is needed to gain a better understanding of the predictors of awareness and attitudes towards POC-PGx testing among Jordanian healthcare professionals.

\section{Data Sharing Statement}

The datasets generated during and/or analyzed during the current study are available from the corresponding author on reasonable request.

\section{Informed Consent Statement}

Informed consent was obtained from all subjects involved in this study.

\section{Institutional Review Board Statement}

The study was conducted according to the guidelines of the Declaration of Helsinki, and approved by the Institutional Review Board (IRB, approval ID: 30/120/ 2019 ) at the Jordan University of Science and Technology's (JUST).

\section{Acknowledgments}

Authors of this work would like to acknowledge the support received form Deanship of Scientific Research at Jordan University of Science \& Technology.

\section{Author Contributions}

All authors made substantial contributions to conception and design, acquisition of data, or analysis and interpretation of data; took part in drafting the article or revising it critically for important intellectual content; agreed to submit to the current journal; gave final approval of the version to be published; and agree to be accountable for all aspects of the work. 


\section{Funding}

This work was supported by the Deanship of Scientific Research at Jordan University of Science and Technology [grant number 156/2019].

\section{Disclosure}

There are no conflicts of interest associated with this publication and no financial support that could have influences its reported results.

\section{References}

1. Huang RS, Ratain MJ. Pharmacogenetics and pharmacogenomics of anticancer agents. CA Cancer J Clin. 2009;59(1):42-55. doi:10.3322/ caac. 20002

2. Haga SB, Moaddeb J. Comparison of delivery strategies for pharmacogenetic testing services. Pharmacogenet Genomics. 2014;24 (3):139. doi:10.1097/FPC.0000000000000028

3. Saldivar J-S, Taylor D, Sugarman EA, et al. Initial assessment of the benefits of implementing pharmacogenetics into the medical management of patients in a long-term care facility. Pharmgenomics Pers Med. 2016;9:1. doi:10.2147/PGPM.S93480

4. Ventola CL. Role of pharmacogenomic biomarkers in predicting and improving drug response: part 1: the clinical significance of pharmacogenetic variants. Pharmacol Ther. 2013;38(9):545.

5. Knisely MR, Carpenter JS, Von Ah D. Pharmacogenomics in the nursing literature: an integrative review. $J$ Nurs Outlook. 2014;62 (4):285-296. doi:10.1016/j.outlook.2014.03.004

6. Cabello AJ, Gavilán ED, Jiménez FJ, Rodríguez CM, Del Castillo JDD, Cañas EP. Drug-related mortality among inpatients: a retrospective observational study. Eur J Clin Pharmacol. 2016;72 (6):731-736. doi:10.1007/s00228-016-2026-0

7. Nivya K, Sri Sai Kiran V, Ragoo N, Jayaprakash B, Sonal Sekhar M. Systemic review on drug related hospital admissions - a pubmed based search. Saudi Pharm J. 2015;23(1):1-8. doi:10.1016/j. jsps.2013.05.006

8. Pirmohamed M, James S, Meakin S, et al. Adverse drug reactions as cause of admission to hospital: prospective analysis of 18820 patients. BMJ. 2004;329(7456):15-19. doi:10.1136/bmj.329.7456.15

9. Hoop JG, Lapid MI, Paulson RM, Roberts LW. Clinical and ethical considerations in pharmacogenetic testing: views of physicians in 3 "early adopting" departments of psychiatry. J Clin Psychiatry. 2010;71(6):745-753. doi:10.4088/JCP.08m04695whi

10. Thompson C, Hamilton SP, Hippman C. Psychiatrist attitudes towards pharmacogenetic testing, direct-to-consumer genetic testing, and integrating genetic counseling into psychiatric patient care. Psychiatry Res. 2015;226(1):68-72. doi:10.1016/j. psychres.2014.11.044

11. Haddy CA, Ward HM, Angley MT, McKinnon RA. Consumers' views of pharmacogenetics - a qualitative study. Res Social Adm Pharm. 2010;6(3):221-231. doi:10.1016/j.sapharm.2009.08.002

12. Perlis RH, Patrick A, Smoller JW, Wang PS. When is pharmacogenetic testing for antidepressant response ready for the clinic? A costeffectiveness analysis based on data from the STAR* D study. Neuropsychopharmacology. 2009;34(10):2227-2236. doi:10.1038/ npp. 2009.50

13. Priest VL, Begg EJ, Gardiner SJ, et al. Pharmacoeconomic analyses of azathioprine, methotrexate and prospective pharmacogenetic testing for the management of inflammatory bowel disease. Pharmacoeconomics. 2006;24(8):767-781. doi:10.2165/00019053200624080-00004
14. Haga SB, Burke W, Ginsburg GS, Mills R, Agans RJ. Primary care physicians' knowledge of and experience with pharmacogenetic testing. Clin Genet. 2012;82(4):388-394. doi:10.1111/j.13990004.2012.01908.x

15. Rogausch A, Prause D, Schallenberg A, Brockmöller J, Himmel W. Patients' and physicians' perspectives on pharmacogenetic testing. Pharmacogenomics. 2006;7(1):49-59. doi:10.2217/14622416.7.1.49

16. Ielmini M, Poloni N, Caselli I, et al. The utility of pharmacogenetic testing to support the treatment of bipolar disorder. Pharmgenomics Pers Med. 2018;11:35.

17. Ielmini M, Poloni N, Caselli I, Diurni M, Grecchi A, Callegari C. The role of pharmacogenetic testing in the treatment of bipolar disorder: preliminary results. Minerva Psichiatr. 2018;59(1):10-15.

18. Roberts JD, Wells GA, Le May MR, et al. Point-of-care genetic testing for personalisation of antiplatelet treatment (RAPID GENE): a prospective, randomised, proof-of-concept trial. Lancet. 2012;379 (9827):1705-1711. doi:10.1016/S0140-6736(12)60161-5

19. Louie RF, Tang Z, Shelby DG, Kost GJJ. Point-of-care testing: millennium technology for critical care. Lab Med. 2000;31 (7):402-408.

20. Haga SB. Challenges of development and implementation of point of care pharmacogenetic testing. Expert Rev Mol Diagn. 2016;16 (9):949-960. doi:10.1080/14737159.2016.1211934

21. Howard R, Leathart JBS, French DJ, et al. Genotyping for CYP2C9 and VKORC1 alleles by a novel point of care assay with HyBeacon ${ }^{\circledR}$ probes. Clin Chim Acta. 2011;412(23-24):2063-2069. doi:10.1016/j. cca.2011.07.013

22. Shahabi P, Siest G, Visvikis-Siest SJP. Clinical interest of point-ofcare pharmacogenomic testing: clopidogrel behind warfarin. Pharmacogenomics. 2012;13(11):1215-1218. doi:10.2217/pgs.12.85

23. Epstein RS, Moyer TP, Aubert RE, et al. Warfarin genotyping reduces hospitalization rates results from the MM-WES (Medco-Mayo Warfarin Effectiveness study). $J$ Am Coll of Cardiol. 2010;55(25):2804-2812. doi:10.1016/j.jacc.2010.03.009

24. Nutescu EA, Drozda K, Bress AP, et al. Feasibility of implementing a comprehensive warfarin pharmacogenetics service. Pharmacotherapy. 2013;33(11):1156-1164. doi:10.1002/phar.1329

25. Jarrar YJ. Perception of primary care physicians' toward pharmacogenetics in Jordan. Jordan Med J. 2019;53(3):81-89.

26. Table of pharmacogenomic biomarkers in drug labeling. 2021. Available from: https://www.fda.gov/drugs/science-and-researchdrugs/table-pharmacogenomic-biomarkers-drug-labeling. Accessed May 8, 2021.

27. Stanek E, Sanders C, Taber KAJ, et al. Adoption of pharmacogenomic testing by US physicians: results of a nationwide survey. Clin Pharmacol Ther. 2012;91(3):450-458. doi:10.1038/ clpt.2011.306

28. Rogers EM. Diffusion of Innovations. Simon and Schuster; 2010.

29. Sahin IJ. Detailed review of Rogers' diffusion of innovations theory and educational technology-related studies based on Rogers' theory. Turkish Online J Educ Technol. 2006;5(2):14-23.

30. Taber KAJ, Dickinson BD. Pharmacogenomic knowledge gaps and educational resource needs among physicians in selected specialties. Pharmgenomics Pers Med. 2014;7:145.

31. Accreditation Council for Pharmacy Education. Accreditation Standards and Key Elements for the Professional Program in Pharmacy Leading to the Doctor of Pharmacy Degree. Chicago, IL: Accreditation Council for Pharmacy Education; 2015.

32. Adams SM, Anderson KB, Coons JC, et al. Advancing pharmacogenomics education in the Core PharmD curriculum through student personal genomic testing. Am J Pharm Educ. 2016;80(1):1. doi: $10.5688 /$ ajpe 8013

33. Ma TKW, Lam -Y-Y, Tan VP, Yan BP. Variability in response to clopidogrel: how important are pharmacogenetics and drug interactions? $\mathrm{Br} \quad \mathrm{J}$ Clin Pharmacol. 2011;72(4):697-706. doi:10.1111/j.1365-2125.2011.03949.x 
34. Roederer MW, Van Riper M, Valgus J, Knafl G, McLeod H. Knowledge, attitudes and education of pharmacists regarding pharmacogenetic testing. Pers Med. 2012;9(1):19-27. doi:10.2217/ pme. 11.87

35. Raosoft Io. Raosoft. Sample size calculator. 2014. Available from: http://www.raosoft.com/samplesize.html. Accessed May 8, 2021.

36. Jordan Medical Association (JMA). Annual report Amman. 2021 Available from: http://www.jma.org.jo/Contents/Annual_Reportar aspx. Accessed May 8, 2021.

37. Stanek EJ, Sanders CL, Frueh FW. Physician awareness and utilization of Food and Drug Administration (FDA)-approved labeling for pharmacogenomic testing information. $J$ Pers Med. 2013;3 (2):111-123. doi:10.3390/jpm3020111

38. Powell KP, Cogswell WA, Christianson CA, et al. Primary care physicians' awareness, experience and opinions of direct-toconsumer genetic testing. J Genet Couns. 2012;21(1):113-126. doi:10.1007/s10897-011-9390-9

39. Dressler LG, Deal AM, Patel J, Markey J, Riper MV, McLeod HL. Cancer pharmacogenomics, adoption by oncologists and patient benefit. Per Med. 2014;11(2):143-153. doi:10.2217/pme.14.1

40. Shields AE, Blumenthal D, Weiss KB, Comstock CB, Currivan D, Lerman C. Barriers to translating emerging genetic research on smoking into clinical practice: perspectives of primary care physicians. J Gen Intern Med. 2005;20(2):131-138. doi:10.1111/ j.1525-1497.2005.30429.x
41. Rahma AT, Elsheik M, Ali BR, et al. Knowledge, attitudes, and perceived barriers toward genetic testing and pharmacogenomics among healthcare workers in the United Arab Emirates: a Cross-Sectional Study. J Pers Med. 2020;10(4):216.

42. Albassam A, Alshammari S, Ouda G, Koshy S, Awad A, Rovers J. Knowledge, perceptions and confidence of physicians and pharmacists towards pharmacogenetics practice in Kuwait. PLoS One. 2018;13(9):e0203033. doi:10.1371/journal.pone.0203033

43. Walden LM, Brandl EJ, Changasi A, et al. Physicians‘ opinions following pharmacogenetic testing for psychotropic medication. Psychiatry Res. 2015;229(3):913-918. doi:10.1016/j. psychres.2015.07.032

44. Moaddeb J, Mills R, Haga SB. Community pharmacists' experience with pharmacogenetic testing. $J$ Am Pharm Assoc. 2015;55 (6):587-594. doi:10.1331/JAPhA.2015.15017

45. Klitzman R, Chung W, Marder K, et al. Attitudes and practices among internists concerning genetic testing. $J$ Genet Couns. 2013;22(1):90-100. doi:10.1007/s10897-012-9504-Z

46. Callegari C, Isella C, Caselli I, Poloni N, Ielmini M. Pharmacogenetic tests in reducing accesses to emergency services and days of hospitalization in bipolar disorder: a 2-year mirror analysis. J Pers Med. 2019;9(2):22. doi:10.3390/jpm9020022

\section{Publish your work in this journal}

Pharmacogenomics and Personalized Medicine is an international, peer-reviewed, open access journal characterizing the influence of genotype on pharmacology leading to the development of personalized treatment programs and individualized drug selection for improved safety, efficacy and sustainability. This journal is indexed on the American Chemical Society's Chemical Abstracts Service (CAS). The manuscript management system is completely online and includes a very quick and fair peer-review system, which is all easy to use. Visit http://www.dovepress.com/testimonials.php to read real quotes from published authors. 